\title{
Subchronic Early Life Arsenic Exposure at Low Doses Impaired the Biogenic Amine Neurotransmitter and Nitric Oxide Levels in Different Brain Regions of Rats
}

\author{
Lalit P Chandravanshi ${ }^{1,2^{*}}$ and Devendra K Patel $^{3}$
}

${ }^{1}$ Department of Zoology, Institute of Science, Banaras Hindu University, Varanasi, 221005, India

${ }^{2}$ Developmental Toxicology Division, CSIR-Indian Institute of Toxicology Research, Post Box No. 80, MG Marg, Lucknow, 226 001, India

${ }^{3}$ Analytical Chemistry Division, CSIR-Indian Institute of Toxicology Research, Post Box No. 80, MG Marg, Lucknow, 226 001, India

\begin{abstract}
Current approaches to risk assessment assume the neurotoxic response for arsenic at the low doses while the mechanism of arsenic-induced developmental neurotoxicity is unknown. Because of this, our previous studies point out that arsenic-induced cholinergic and dopaminergic dysfunctions with associated behavior and also observed the persistent effects were more pronounced in dopaminergic system in early life exposed rats. In continuation of previous studies, rats were exposed to arsenic in drinking water at low doses $(2$ or $4 \mathrm{mg} / \mathrm{kg}$ ) during early life. Here, we investigated that alteration in the levels of biogenic amines and their metabolites (norepinephrine (NE), epinephrine (EPN), dopamine (DA), 3, 4-Dihydroxyphenylacetic acid (DOPAC), Homovanillic acid (HVA) and 5-hydroxytryptamine (5-HT) by using reversed phase high performance liquid chromatography in different brain regions of arsenic exposed rats on PD60 as compared to controls and furthermore determine persistent effect of arsenic after withdrawal of exposure. Levels of nitric oxide (NO) were also declines in brain regions of arsenic-treated rats in different brain regions of early life exposed rats. Arsenic has been found to modulate the monoaminergic and nitrergic systems during the critical periods of brain development; however, these modifications get more compromised in corpus striatum than frontal cortex and hippocampus even after withdrawal of exposure on PD90 as compared to controls. Modification at the level of biogenic amines and NO in certain brain regions would provide opportunities for the development of therapeutics tools for minimizing developmental neurotoxicity.
\end{abstract}

Keywords: Biogenic amines; Nitric oxide; Early life; Corpus striatum; High-performance liquid chromatography

\section{Introduction}

Arsenic is a heavy metalloid that can exist in biological systems in many different inorganic and organic compounds with several oxidation states, the most common being the trivalent and pentavalent forms [1]. The majority of the epidemiological studies of arsenic are associated with exposure to inorganic arsenic compounds through drinking water. Pentavalent arsenic has been reported in the surface water and trivalent arsenic in the ground water, which suggests this, is the most common reason for the humans generally being exposed to trivalent arsenic [2]. Arsenic is a major global health alarm due to its wide distribution and adverse health effects on the human body. The people of the large portions of the world are being exposed to arsenic through drinking water or ingestion of food materials and causing serious health effects involving the dermal, gastrointestinal, nervous, hepatic, renal, cardiovascular, respiratory, hematopoietic and ophthalmic systems [38]. In contrast to other physiological systems of the body, the nervous system appears to be the most vulnerable and the main target for arsenicinduced neurotoxicity [9]. Central nervous system and the peripheral nervous system both are commonly affected by the arsenic exposure [10], however, the effects of arsenic exposure on the peripheral nervous system are more prominent in adults while the arsenic significantly affects the central nervous system during the crucial phase of brain development.

It has been proved that arsenic can easily cross the placental barrier to the fetus [11] and even moderate exposure to arsenic during pregnancy and early life is linked with various adverse health outcomes, including neurological problems in the fetus $[12,13]$ and children's $[14,15]$. Further, the various human population-based studies found that arsenic concentrations in urine were inversely associated with
Verbal IQ, Performance IQ and processing speed problems in children's [16-20]. Exposure occurred during gestation is associated with adverse effects on the fetus including premature and low birth weight of infants, spontaneous abortion [21,22], increased risk of birth defects [23] and reduced fetal size even at low to moderate levels of arsenic.

The accumulation property of arsenic in the brain is the prime reason for its prolonged persistence in the brain. The presence of arsenic in the brain causes various dysfunctions of the nervous system through several mechanisms and alters the development of the nervous system. Oxidative stress destroyed the balance between pro-oxidant and antioxidant system and it has been one of the main mechanism in the neurotoxicity and also a loss of brain functions. In our previous studies on early life exposure to arsenic at different concentrations, we reported a behavioural cholinergic and dopaminergic modification with biochemical alterations, such as apoptosis, oxidative stress and antioxidant enzymatic activity of brain tissue [24,25]. Exposure to arsenic in vitro experiments on Murine neuroblastoma cell line caused the enhancement of the reactive oxygen species leading to neuronal cell apoptosis through JNK/ERK-mediated mitochondria-dependent and

*Corresponding author: Lalit P Chandravanshi, Department of Zoology, Institute of Science, Banaras Hindu University, Varanasi, 221005, India, Tel: +91 5426702523 Fax: +91 542 2368174; E-mail: chandravanshi04@gmail.com

Received May 20, 2017; Accepted May 29, 2017; Published June 16, 2017

Citation: Chandravanshi LP, Patel DK (2017) Subchronic Early Life Arsenic Exposure at Low Doses Impaired the Biogenic Amine Neurotransmitter and Nitric Oxide Levels in Different Brain Regions of Rats. J Environ Anal Toxicol 7: 477. doi: 10.4172/2161-0525.1000477

Copyright: ( $) 2017$ Chandravanshi LP, et al. This is an open-access article distributed under the terms of the Creative Commons Attribution License, which permits unrestricted use, distribution, and reproduction in any medium, provided the original author and source are credited. 
Citation: Chandravanshi LP, Patel DK (2017) Subchronic Early Life Arsenic Exposure at Low Doses Impaired the Biogenic Amine Neurotransmitter and Nitric Oxide Levels in Different Brain Regions of Rats. J Environ Anal Toxicol 7: 477. doi: 10.4172/2161-0525.1000477

GRP 78/CHOP-regulated pathways [26]. Moreover, some studies have also confirmed the neuronal apoptosis contributing to the development of many human diseases including neurodegenerative diseases $[27,28]$.

A lot of Information regarding the disturbance on biogenic amines in adults by arsenic at high doses has been reported [29-31], while the information about the effect of arsenic on biogenic amine at low doses during crucial period of brain development is scanty. However, mechanisms underlying the developmental neurotoxicity of arsenic are indistinct and the research on neurobiological consequences of arsenic exposure is important to understand the mechanism of developmental neurotoxicity. Impairment of neurotransmitters functions in the central nervous system (CNS) is closely related to neurodegenerative disease, learning, and memory impairment. Therefore, studying the impairment of biogenic amine and their metabolites in the brain of rats is extremely considerable to understand the developmental neurotoxicity of arsenic. Developmental exposure to arsenic affects the release, synthesis, uptake of neurotransmitter and receptor expression could be deleterious and lead to long-term behavioral deficits [32-34]. Levels of some neurotransmitters and the activity of enzymes related to neurotransmitter metabolism, such as cholinesterase and dopamine b-hydroxylase, in the brain of rodents were found to be altered after exposure to arsenic [34-37].

NO may also regulate the neurotransmitter release and the intercellular neurochemical signaling which is involved in neuronal plasticity, learning and memory [38-40]. Impairment in NO-related function may also contribute to the cognitive deficits in children and adolescents exposed to arsenic $[17,41]$. Rios et al. [35] have reported the decreased NO markers associated with the morphological changes in the brain of rats exposed to arsenic. Several nitrergic markers deficit has been observed in blood and brain tissue of rats and rabbits that may be playing a significant role in the arsenic-induced neurotoxicity [42,43]. However, an impact of arsenic exposure on the biogenic amines and NO levels are not understood during crucial periods of brain development. Moreover, it is not understood whether these changes are transient or persistent after the withdrawal of arsenic exposure. Therefore, we aimed to assess the association between impairment of these functions and arsenic exposure at low doses during the early life crucial period of brain development. The present study may be useful in disclosing the mechanism of developmental neurotoxicity of arsenic and suggesting the occurrence of developmental neurotoxicity is associated with changes of biogenic amines and their metabolites and NO in CNS.

\section{Materials and Methods}

\section{Animals and treatment}

Early life exposure of rats to sodium arsenite: Male Wistar rats (21 days old) were obtained from the central animal breeding colony of CSIR-Indian Institute of Toxicology Research (CSIR-IITR), Lucknow, India. All the animals were maintained on a commercial pellet diet and water ad libitium, housed in plastic cages with bedding at a temperature $\left(22 \pm 2^{\circ} \mathrm{C}\right)$ controlled room with a $12 / 12 \mathrm{~h}$ light/dark cycle. All experimental procedures involving animals were carried out strictly accordance with the international care guidelines for animals approved by the Ministry of Environment and Forests (Government of India), New Delhi, India. Further, male rats were randomly divided into three groups on PD22. Group I rats were treated with normal saline (p.o.) identically as in groups II and III and served as controls. Group II and Group III rats were treated daily with one dose per day sodium arsenite 2 or $4 \mathrm{mg} / \mathrm{kg}$ body weight, p.o. respectively from PD22 to PD59.
On PD60, control and treated rats were sacrificed and brains were taken out from skull quickly and washed in ice-cold saline. The frontal cortex corpus striatum and hippocampus regions of the brain were carefully separated, following the method as described by Glowinski et al. [44]. The brain regions were kept frozen at $-80^{\circ} \mathrm{C}$ for the estimation of biogenic amines and their metabolites and levels of NO.

To understand whether these changes were transient or persistent after withdrawal of arsenic exposure, early life exposed rats were left for 30 days and monitored daily. Neurotoxic effects of arsenic on biogenic amines and their metabolites and levels of NO were studied on PD60 and PD90.

\section{Estimation of biogenic amines and their metabolites in brain regions of rats}

To determine the levels of DA, NE, EPN, 5-HT, DOPAC and HVA in different brain regions of rats, reversed-phase high-performance liquid chromatography coupled with an electrochemical detector (HPLC-ECD) was carried out following the method described by Kim et al. [45] with some modifications. The HPLC system (Waters, Melford, USA) was integrated with a high-pressure isocratic pump (515 HPLC Pump), a sample injector valve, C-18 reverse phase column $(250 \times 4$ $\mathrm{mm}$, particle size $5 \mu \mathrm{m}$ ) and an electrochemical detector (464 Pulsed electrochemical detector). The frozen brain tissue sample was weighed and transferred into the tube and added the pre-chilled homogenize buffer solution (0.1 M Perchloric acid and 3,4- dihydroxy benzylamine, an internal standard at a final concentration of $25 \mathrm{ng} / \mathrm{ml}$ ) at a volume of $1 \mathrm{ml} / 100 \mathrm{mg}$ sample. Brain tissues were homogenized and kept on ice for $15 \mathrm{~min}$. The homogenate was centrifuged at maximal speed $(36,000$ $\mathrm{xg}$ ) at $4^{\circ} \mathrm{C}$ for $10 \mathrm{~min}$ and the supernatant was collected and transferred to a new sample tube. The supernatant was filtered through nylon filters $(0.25 \mathrm{~mm}$, Millipore, USA) and used for the estimation of biogenic amines and their metabolites.

$20 \mu \mathrm{l}$ volume of the sample was injected into a reverse-phase analytical column with a mobile phase $(\mathrm{pH} 4.2)$ containing sodium dihydrogen phosphate $(0.15 \mathrm{M})$, ethylenediaminetetraacetic acid $(0.25$ $\mathrm{mM})$, sodium octyl sulfate $(1.75 \mathrm{mM})$ and $4 \%$ methanol at the flow rate of $1.5 \mathrm{ml} / \mathrm{min}$. The concentrations of biogenic amines and their metabolites in different brain regions of rats were determined by using an electrochemical detector coupled with an integrator. Chromatograms were analyzed with the help of Empower2 software (Waters, Melford, USA) and results were expressed in $\mathrm{ng} / \mathrm{g}$ tissue weight.

\section{Estimation of NO levels in brain regions of rats}

NO level in different brain regions of rats was analyzed using NO assay kit procured commercially (Calbiochem, USA). The assay principle is based on the conversion of nitrate to nitrite by the enzymatic action of nitrate reductase. Nitrate is converted into a fluorescent compound $1(\mathrm{H})$-naphthotriazole after the addition of 2,3-diaminonaphthalene and sodium hydroxide. The emitted fluorescence was measured spectrofluorimetrically (excitation $430 \mathrm{~nm} /$ emission $450 \mathrm{~nm}$ ) using a multiwell plate reader (Biotek Synergy HT, USA) [46]. The measured values were expressed in pmoles nitrate/mg tissue weight.

\section{Protein estimation}

Protein content in samples was measured following the method described by Lowry et al. [47] using bovine serum albumin as a reference standard. 
Citation: Chandravanshi LP, Patel DK (2017) Subchronic Early Life Arsenic Exposure at Low Doses Impaired the Biogenic Amine Neurotransmitter and Nitric Oxide Levels in Different Brain Regions of Rats. J Environ Anal Toxicol 7: 477. doi: 10.4172/2161-0525.1000477

Page 3 of 8

\section{Statistical analysis}

In the present study Graph Pad prism software has been used to analyze data of biogenic amine and their metabolites and levels of NO. One way analysis of variance (ANOVA) followed by Newman-Keuls test has been used to analyzed the data for posthoc comparisons. Values up to $\mathrm{p}<0.05$ have been considered significant.

\section{Results}

\section{Effects on biogenic amines and their metabolites in brain} regions of rats on PD60 and PD90

The levels of biogenic amines and their metabolites showed dose dependent changes in the frontal cortex, corpus striatum and hippocampus of arsenic exposed rats as compared to controls. In comparison to controls, the administration of both doses of arsenic has increased the levels of DA $(16 \%, \mathrm{p}<0.05 ; 39 \%, \mathrm{p}<0.05)$, EPN ( $46 \%$, $\mathrm{p}<0.05 ; 59 \%, \mathrm{p}<0.01), \mathrm{NE}(18 \%, \mathrm{p}<0.05 ; 39 \%, \mathrm{p}<0.01 ;)$ and decreased the level of DOPAC $(19 \%, \mathrm{p}<0.05 ; 29 \%, \mathrm{p}<0.01)$, HVA $(20 \%, \mathrm{p}<0.05 ; 36 \%$, $\mathrm{p}<0.01$ ) on PD60 (Table 1). The arsenic exposed rats showed a trend of recovery in the levels of DA $(6 \%, \mathrm{p}>0.05 ; 14 \%, \mathrm{p}<0.05), \mathrm{NE}(5 \%, \mathrm{p}>0.05$; $8 \%, p>0.05)$, EPN (11\%, p $>0.05 ; 15 \%, p>0.05)$, DOPAC $(6 \%, p>0.05$; $10 \%, \mathrm{p}>0.05)$, and HVA $(9 \%, \mathrm{p}>0.05 ; 15 \%$; $>0.05)$ in frontal cortex even at 30 days after withdrawal of arsenic exposure in comparison to respective controls (Table 1). No significant change was observed in the level of 5-HT in frontal cortex of arsenic-treated rats as compared to controls.

A significant increase in the levels of DA $(29 \% \mathrm{p}<0.05 ; 64 \%$, $\mathrm{p}<0.01)$, HVA $(22 \%, \mathrm{p}<0.05 ; 49 \%, \mathrm{p}<0.01)$ and decrease in the levels of NE $(22 \%, \mathrm{p}<0.05 ; 35 \%, \mathrm{p}<0.05), \mathrm{EPN}(24 \%, \mathrm{p}<0.05 ; 35 \%, \mathrm{p}<0.05)$ and
DOPAC $(25 \%, \mathrm{p}<0.05 ; 36 \%, \mathrm{p}<0.01)$ were observed in corpus striatum of rats exposed to arsenic ( $2.0 \mathrm{or} 4.0 \mathrm{mg} / \mathrm{kg}$ body weight) from PD2259 on PD60 in comparison to controls (Table 2). A trend of recovery in the levels of DA $(19 \%, \mathrm{p}>0.05 ; 37 \%, \mathrm{p}<0.05), \mathrm{NE}(14 \%, \mathrm{p}>0.05 ; 24 \%$, $\mathrm{p}<0.05)$, EPN (16\%, p >0.05; 24\%, p<0.05), DOPAC $(5 \%, \mathrm{p}>0.05 ; 14 \%$, $\mathrm{p}<0.05)$ and HVA $(21 \%, \mathrm{p}<0.05 ; 29 \%$; $\mathrm{p}<0.05)$ were seen in the corpus striatum of arsenic-treated rats. The changes were found to persist at the higher dose 30 days after withdrawal of exposure on PD90 in comparison to respective controls (Table 2). The level of 5-HT was not significantly impaired in corpus striatum of arsenic-treated rats.

Exposure with arsenic to rats caused a significant increase in the levels of DA $(19 \%, \mathrm{p}<0.05 ; 28 \%, \mathrm{p}<0.05)$, NE $(17 \%, \mathrm{p}<0.05 ; 35 \%$, $\mathrm{p}<0.01)$, EPN (23\%, $<<0.05 ; 59 \%, \mathrm{p}<0.05)$ and decrease in the levels of DOPAC $(26 \%, \mathrm{p}<0.05 ; 32 \%, \mathrm{p}<0.05)$ and HVA $(26 \%, \mathrm{p}<0.05 ; 33 \%$, $\mathrm{p}<0.05$ ) in hippocampus on PD60 as compared to controls (Table 3). The animals were appeared to be recovered from the toxic effects of arsenic 30 days after withdrawal of exposure as no significant variation in the levels of NE $(2 \%, \mathrm{p}>0.05 ; 4 \%, \mathrm{p}>0.05)$, EPN $(10 \%, \mathrm{p}>0.05 ; 16 \%$, $\mathrm{p}>0.05)$, DOPAC $(5 \%, \mathrm{p}>0.05 ; 12 \%, \mathrm{p}>0.05)$, and HVA $(2 \%, \mathrm{p}>0.05$; $6 \% ; p>0.05)$ were observed. The levels of DA $(9 \%, p>0.05 ; 19 \%, p<0.05)$ was found to be significantly remained to persist at the higher dose of arsenic in the hippocampus of arsenic exposed rats 30 days after withdrawal of exposure on PD90 in comparison to respective controls (Table 3). The hippocampal level of 5-HT was not significantly altered in arsenic exposed rats on PD60 and 30 days after withdrawal of arsenic exposure as compared to controls.

\section{Effect on the level of NO in different brain regions of rats on PD60 and PD90}

A significant decrease in the levels of NO in frontal cortex (1.57-

\begin{tabular}{|c|c|c|c|}
\hline \multirow{2}{*}{ Age/ Biogenic amine (s)/ Metabolite (s) } & \multirow[b]{2}{*}{ Control } & \multicolumn{2}{|c|}{ Treatment groups } \\
\hline & & $\begin{array}{c}\text { ARS I } \\
(2 \mathrm{mg} / \mathrm{kg})\end{array}$ & $\begin{array}{c}\text { ARS II } \\
(4 \mathrm{mg} / \mathrm{kg})\end{array}$ \\
\hline \multicolumn{4}{|l|}{ Postnatal day 60} \\
\hline Dopamine & $1103 \pm 69.53$ & $1281 \pm 67.60^{*}$ & $1541 \pm 81.63^{*}$ \\
\hline Norepinephrine & $294.90 \pm 27.70$ & $348.30 \pm 8.05^{\star}$ & $411.90 \pm 14.70^{* \star}$ \\
\hline Epinephrine & $349.40 \pm 38.58$ & $513.70 \pm 43.08^{*}$ & $555.50 \pm 38.97^{\star \star}$ \\
\hline Serotonin & $956.80 \pm 70.18$ & $1004 \pm 90.04$ & $1105 \pm 106.90$ \\
\hline DOPAC & $326.50 \pm 17.40$ & $264.40 \pm 14.19^{*}$ & $229.40 \pm 9.50^{\star *}$ \\
\hline Homovanillic acid & $124.10 \pm 2.88$ & $99.09 \pm 6.02^{\star}$ & $79.14 \pm 2.70^{\star \star}$ \\
\hline \multicolumn{4}{|l|}{ Postnatal day 90} \\
\hline Dopamine & $1146 \pm 132.90$ & $1224 \pm 154.50$ & $1335 \pm 108.20^{*}$ \\
\hline Norepinephrine & $227.50 \pm 12.44$ & $240.90 \pm 9.34$ & $246.60 \pm 15.46$ \\
\hline Epinephrine & $369 \pm 23.44$ & $410.30 \pm 32.56$ & $427.30 \pm 24.69$ \\
\hline Serotonin & $907.50 \pm 98.09$ & $860.40 \pm 69.42$ & $844.70 \pm 88.32$ \\
\hline DOPAC & $445.40 \pm 19.58$ & $416.80 \pm 51.87$ & $401.80 \pm 20.42$ \\
\hline Homovanillic acid & $114.70 \pm 20.44$ & $103.90 \pm 10.75$ & $97.41 \pm 9.64$ \\
\hline
\end{tabular}

Table 1: Early life exposure (PD22-PD59) to sodium arsenite and its effect on biogenic amines and their metabolites in frontal cortex of rats on PD60 and PD90.

Rats were exposed to sodium arsenite (ARS I-2.0 or ARS II-4.0 mg/kg body weight/ day, p.o.). Effect on biogenic amine and their metabolites studied on PD60 and 30 days after withdrawal of exposure on PD90. Values are mean \pm SEM of five animals in each group. Data have been analyzed by one-way analysis of variance followed by Newman-Keuls test. *Significantly differs from controls $(p<0.05)$; ${ }^{* *}$ Significantly differs from controls $(p<0.01)$ and the values are expressed as ng/g tissue weigh 
Citation: Chandravanshi LP, Patel DK (2017) Subchronic Early Life Arsenic Exposure at Low Doses Impaired the Biogenic Amine Neurotransmitter and Nitric Oxide Levels in Different Brain Regions of Rats. J Environ Anal Toxicol 7: 477. doi: 10.4172/2161-0525.1000477

Page 4 of 8

\begin{tabular}{|c|c|c|c|}
\hline \multirow[t]{2}{*}{ Age/ Biogenic amine (s)/ Metabolite (s) } & \multirow{2}{*}{$\begin{array}{l}\text { Control } \\
\text { Control }\end{array}$} & \multicolumn{2}{|c|}{$\begin{array}{c}\text { Treatment groups } \\
\text { ARS I } \\
\text { ARS II }\end{array}$} \\
\hline & & ARS I ( $2 \mathrm{mg} / \mathrm{kg})$ & ARS II $(4 \mathrm{mg} / \mathrm{kg})$ \\
\hline \multicolumn{4}{|l|}{ Postnatal day 60} \\
\hline Dopamine & $5360 \pm 456.30$ & $6944 \pm 319.80^{*}$ & $8800 \pm 818.10^{* *}$ \\
\hline Norepinephrine & $595.90 \pm 61.87$ & $460.10 \pm 25.47^{*}$ & $386.40 \pm 9.69^{\star}$ \\
\hline Epinephrine & $363.80 \pm 16.31$ & $274.80 \pm 9.79^{*}$ & $234.90 \pm 25.73^{*}$ \\
\hline Serotonin & $779.20 \pm 86.87$ & $860.50 \pm 125.20$ & $907.80 \pm 9.24$ \\
\hline DOPAC & $3216 \pm 183.90$ & $2380 \pm 151.60^{\star *}$ & $2033 \pm 152.70^{\star *}$ \\
\hline Homovanillic acid & $594.80 \pm 44.90$ & $731.40 \pm 34.01^{*}$ & $889.40 \pm 46.94^{\star *}$ \\
\hline \multicolumn{4}{|l|}{ Postnatal day 90} \\
\hline Dopamine & $5068 \pm 272$ & $6064 \pm 277.90$ & $6986 \pm 481.10^{*}$ \\
\hline Norepinephrine & $403.70 \pm 26.10$ & $344.70 \pm 10.93$ & $304.40 \pm 10.83^{*}$ \\
\hline Epinephrine & $311.10 \pm 40.26$ & $258.70 \pm 12.33$ & $234.70 \pm 10.56^{*}$ \\
\hline Serotonin & $663.50 \pm 64.17$ & $689.50 \pm 97.66$ & $710.10 \pm 167.50$ \\
\hline DOPAC & $4484 \pm 187.40$ & $4236 \pm 65.44$ & $3818 \pm 139.20^{*}$ \\
\hline Homovanillic acid & $648.70 \pm 37.55$ & $790.20 \pm 57.85$ & $842.80 \pm 58.57^{*}$ \\
\hline
\end{tabular}

Table 2: Early life exposure (PD22 - PD59) to sodium arsenite and its effect on biogenic amines and their metabolites in corpus striatum of rats on PD60 and PD90.

\begin{tabular}{|c|c|c|c|}
\hline \multirow[t]{2}{*}{ Age/ Biogenic amine (s)/ Metabolite (s) } & \multirow[t]{2}{*}{ Control } & \multicolumn{2}{|c|}{$\begin{array}{c}\text { Treatment groups } \\
\text { ARS I } \\
\text { ARS II }\end{array}$} \\
\hline & & ARS I (2 mg/kg) & ARS II (4 mg/kg) \\
\hline \multicolumn{4}{|l|}{ Postnatal day 60} \\
\hline Dopamine & $450 \pm 40.16$ & $511.60 \pm 7.64^{*}$ & $579.70 \pm 36.54^{*}$ \\
\hline Norepinephrine & $197.90 \pm 7.93$ & $231 \pm 12.18^{*}$ & $267.30 \pm 3.67^{\star *}$ \\
\hline Epinephrine & $278.70 \pm 23.17$ & $344.40 \pm 27.37^{*}$ & $444.60 \pm 40.43^{*}$ \\
\hline Serotonin & $396.40 \pm 47.24$ & $359 \pm 42.24$ & $347 \pm 12.53$ \\
\hline DOPAC & $31.55 \pm 0.83$ & $23.14 \pm 1.72^{*}$ & $21.38 \pm 2.47^{*}$ \\
\hline Homovanillic acid & $33.20 \pm 2.35$ & $27.52 \pm 1.64^{*}$ & $24.83 \pm 1.21^{*}$ \\
\hline \multicolumn{4}{|l|}{ Postnatal day 90} \\
\hline Dopamine & $466.10 \pm 66.77$ & $508.30 \pm 27.09$ & $559.10 \pm 37.91^{*}$ \\
\hline Norepinephrine & $224.10 \pm 10.82$ & $228.40 \pm 11.5$ & $233.90 \pm 17.24$ \\
\hline Epinephrine & $267.30 \pm 24.12$ & $296.70 \pm 14.15$ & $310.10 \pm 19.47$ \\
\hline Serotonin & $417.30 \pm 24.93$ & $403.30 \pm 34.81$ & $396.20 \pm 63$ \\
\hline DOPAC & $45.96 \pm 2.88$ & $43.41 \pm 2.39$ & $40.12 \pm 2.60$ \\
\hline Homovanillic acid & $27.63 \pm 3.64$ & $27.11 \pm 3.34$ & $25.96 \pm 3.31$ \\
\hline
\end{tabular}

Table 3: Early life exposure (PD22 - PD59) to sodium arsenite and its effect on biogenic amines and their metabolites in hippocampus of rats on PD60 and PD90.

fold, $\mathrm{p}<0.001 ; 1.85$-fold, $\mathrm{p}<0.001$ ), corpus striatum (2.08-fold, $\mathrm{p}<0.001$; 3.81-fold, $\mathrm{p}<0.001)$ and hippocampus (2.02-fold, $\mathrm{p}<0.001$; 3.21-fold, $\mathrm{p}<.001)$ were observed in rats treated with arsenic ( $2.0 \mathrm{or} 4.0 \mathrm{mg} / \mathrm{kg}$ body weight) in comparison to controls on PD60 (Figure 1). A trend of recovery was found in the levels of $\mathrm{NO}$ in frontal cortex and hippocampus but the changes were remained persistent at a higher dose of arsenic, 30 days after withdrawal of exposure. Interestingly, the levels of NO in the corpus striatum ( 1.43 fold, $\mathrm{p}<0.001 ; 1.59$ fold, $\mathrm{p}<0.001)$ was remained persistent at both doses of arsenic in comparison to controls on PD90 (Figure 1).

\section{Discussion}

Brain development during prenatal phase represents only one part of the lengthy nervous system developmental process. While the early life, childhood, and adolescence represent windows of remarkable brain changes and maturational processes. Biogenic amines are one of major groups of the neurotransmitters which play important roles in the CNS as major neurotransmitters, being involved in regulating the neurotransmission in the brain and the regulation of cognitive and motor functions, mood, emotional behaviour, including memory 


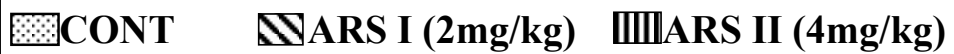
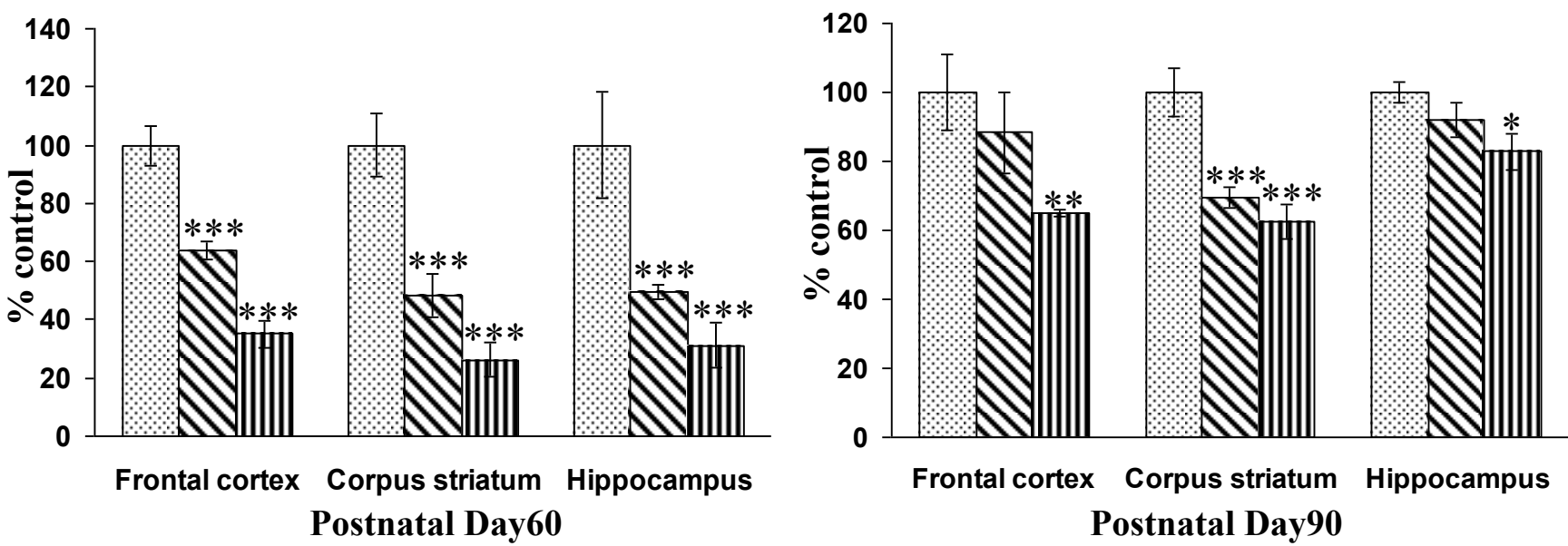

Figure 1: Rats were exposed to sodium arsenite (ARS I-2.0 or ARS II-4.0 mg/kg body weight/ day, p.o.) from PD22 to PD59. Effect on levels of nitric oxide in different brain regions studied on PD60 and 30 days after withdrawal of exposure on PD90. Values are mean \pm SEM of five animals in each group. Data have been analyzed by one-way analysis of variance followed by Newman-Keuls test. *Significantly differs from controls $(p<0.05)$; ** Significantly differs from controls $(p<0.01)$.

[31,48,49]. Many investigators have reported the alteration in biogenic amines and their metabolites in various neurophysiological and neuropsychological diseases [4,50]. Many biogenic amines are essential for the shaping, wiring, brain growth events and the normal development of the nervous system during the critical period of the brain development [51]. Impairment in the levels of biogenic amines (DA, 5-HT, NE) in the brain during critical developmental phases of postnatal could be delayed postnatal maturation of the brain along with neurodevelopmental disturbances associated with cognitive deficits [52-54].

The present study was carried out to investigate the impact of arsenic on the levels of biogenic amines and their metabolites and levels of NO during critical periods of brain development of rats. The level of DA significantly higher was found in the arsenic exposed rats as compared to controls during the postnatal period of brain development in the frontal cortex, corpus striatum and hippocampus of rats at both doses of arsenic. Dose-dependent effect of arsenic on rodents has been observed at low and intermediate doses of arsenic produced hyperactivity whereas the high dose produced hypoactivity along with DA release as increase and decrease in extracellular DA levels $[29,36,55]$, it could be a consequence of dysfunction of the dopaminergic neurotransmitter system. Overproduction of DA can lead to hyperactivity and linked with attention deficit hyperactivity disorder [56]. Weaned mice received to arsenic $(20,40,60$ or 100 ppm) showed a significant correlation between arsenic level and regional monoamine levels in the brain and also found the ACTH levels in plasma were significantly associated with NE concentration in pons and medulla (Delgado et al. 2000). Declined levels of DA while an increase in the levels of NE and 5-HT were reported in the whole brain of guinea pigs after the exposure to arsenic ( $25 \mathrm{mg} / \mathrm{l})$ for 120 days [57].

Further, differential changes in the metabolites of DA (DOPAC and HVA) were observed in selected brain regions due to the arsenic exposure during crucial periods of brain development. Reduced levels of DOPAC were found in selected brain regions of early life arsenic exposed rats. HVA is another metabolite of DA was significantly impaired in frontal cortex and hippocampus of early life arsenic exposed rats. The hippocampal level of HVA was also imparted at both doses $(2$ or $4 \mathrm{mg} / \mathrm{kg})$ in early life arsenic exposed rats. Interestingly, these changes were found to recover, but the levels of DA and their metabolites remained more persistent at a higher dose of arsenic in the corpus striatum of rats, after withdrawal of exposure as compared to controls. These findings showed that an intensity of these changes was more striking in the corpus striatum than the frontal cortex and hippocampus, after withdrawal of exposure. Alteration in the levels of DA and their metabolites (HVA, DOPAC), it might be suggested that the catabolic pathway of DA by catechol-o-methyltransferase might have been influenced by arsenic leading to increased DA degradation [58]. Rodriguez et al. [59] were reported the diminished level of DA, HVA and DOPAC in the corpus striatum of rats after the exposure to mining waste containing mainly arsenic. Hyper-locomotor activity at a low dose ( $3 \mathrm{mg} / \mathrm{kg}$ body weight) and while decreased motor activity in those treated with a high dose of arsenic trioxide $(10 \mathrm{mg} / \mathrm{kg}$ body weight) was observed in mice [60].

In the present study, we observed increased levels of NE in the frontal cortex, hippocampus and decreased level in corpus striatum of early life arsenic exposed rats on PD60. The level of NE was increased may be due to amplifying the activity of the enzyme dopamine hydroxylase, catalyzing the conversion of DA to NE [61]. Alterations in the levels of EPN were also observed in this study, immediately after the arsenic exposure.

Several behavioral and physiological functions such as thermoregulation, mood, sleep, aggression, sexual behaviour, and appetite regulate by the 5 -hydroxytryptamine $(5-\mathrm{HT})(3,27)$. In our study decreased levels of 5-HT were observed in different brain regions of arsenic-treated rats at low doses, however, changes were insignificant. Our findings are in agreement, even at a high dose of arsenic with those of Tripathi et al. [33]. The differential changes in the level of biogenic amines and their metabolites in different brain regions were found might be due to the different duration of exposure and different sensitive period of exposure. These differential changes were more striking in the corpus striatum of the brain after the early life exposure to arsenic and intensity of these modifications were more in the high 
Citation: Chandravanshi LP, Patel DK (2017) Subchronic Early Life Arsenic Exposure at Low Doses Impaired the Biogenic Amine Neurotransmitter and Nitric Oxide Levels in Different Brain Regions of Rats. J Environ Anal Toxicol 7: 477. doi: 10.4172/2161-0525.1000477

Page 6 of 8

dose of arsenic. Based on these finding changes were also more persist in the corpus striatum of rats after the withdrawal of arsenic exposure, suggesting that monoaminergic system in the corpus is found to a more vulnerable target of arsenic-induced neurotoxicity.

The present results indicate that arsenic caused extensive damage to the dopaminergic, adrenergic neurons of the corpus striatum than those of frontal cortex and hippocampus, as the levels of DA, DOPAC, HVA, NE, and EPN remained significantly altered even after withdrawal of exposure. Disturbances in the biogenic amine neurotransmitter levels have also been implicated in the behavioural dysfunction and impaired cognitive performance. Any modifications were observed in DA transmission may negatively effect on several neurological processes and lead to behavioral modifications [36]. Monoamine neurotransmitters (NE, DA, 5-HT) contribute a major role in learning and memory and depressive-like behaviors, therefore any disruption in the neurotransmitter system in the brain after exposed to arsenic might be contributing the abnormal functions of the brain along with impairs various normal physiological functions [34,62]. It has been reported that arsenic interferes with synaptic mechanisms of release of some neurotransmitters, and is responsible for the impairment in various neurotransmitters' systems along with neurobehavioural modifications $[30,37,43]$. The amino acid neurotransmitter has been investigated in immature brain after the realgar treatment in rats indicate that neurotoxicity by the realgar is linked with the disturbance the levels of amino acid neurotransmitters [63]. The amino acid neurotransmitters are closely linked to the vulnerability of the developing brain.

Neuropathy was developed in that human who is exposed to arsenic from long time [64] and also alters the normal functions of central and peripheral nervous systems due to the inhibit the activities of the neurotransmitters- mediating enzymes and their neurotransmitterproducts (DA, 5-HT, NE, and EN). DBH is the most important enzyme in the catecholamine neurotransmitter (catecholamine)-mediating enzyme, which responsible for the catalyzes and biosynthesis of $\mathrm{NE}$ from DA. The DBH activity was found to be decreased in the serum of arsenicosis patients [65]. Inhibition of the activity of DBH in serum considered as a possible index of sympathetic nervous functions.

NO is regulating different functions, including neurotransmission, regulation of blood vessel dilation and the immune response. In the central nervous system, NO play important role in the cell signaling associated with cognitive function, maintenance of synaptic plasticity to neuron and neurosecretion [66-68]. NO act as a neuromodulator and diffuses from one neuron to another neuron directly and is involved in brain development [69]. NO activity in the CNS has an important role in both the physiological and pathological condition and also reported a localization of nNOS in different area of the brain, such as the corpus striatum, medulla, cortex, hippocampus, hypothalamus and the cerebellum of rodents [70-72]. Decreased the nitrites and nitrates in the striatum of rats associated with chronic exposure to arsenite and NO production was also decreased in vitro experiment [43]. Our study too showed decreased NO production in frontal cortex; corpus striatum and hippocampus in arsenic exposed rats may be due to the lower protein levels, which could outcome from declined expression and/or increased degradation. Reduced production of NO suggested that alter the pattern of synapse due to the nitrergic deficit during CNS development.

The finding of the present study indicates that production of NO was remained more decreased in the corpus striatum region compare to other brain regions after the withdrawal of arsenic exposure. Tetrahydrobiopterin levels enhance the ubiquitylation of nNOS and resulting degradation of the protein. Decreased tetrahydrobiopterin levels have been found in arsenic exposed rabbits [42] and this result can also be associated with decreased monoamine levels in arsenicexposed animals [73]. Rios et al. [35] have been observed that decreased the nitrergic functions affecting the structural organization of the brain targeting the cytoskeletal proteins and membranes at lower concentration ( $3 \mathrm{ppm}$ equivalent to $0.4 \mathrm{mg} / \mathrm{kg}$ body weight/day) of arsenic in rats.

The present study demonstrates that low doses of continuous exposure to arsenic during early life are associated with the disturbance in biogenic amine levels and their metabolites. Because of arsenic exposure, the reduction in the level of NO was found in the developing brain, which could modulate the several neurological risk factors. However, further studies are required to establish the arsenic-induced developmental neurotoxicity and by which mechanism changes were more compromised in the corpus striatum region even after withdrawal of arsenic exposure. The results of the present study drag attention to these CNS effects of arsenic even at low doses, besides the more general damaging effects of arsenic reported at a higher dose of arsenic in other models. Further, the continuous exposure to arsenic during critical periods of brain development may be an important risk factor for increased vulnerability to neurodegenerative diseases.

\section{Acknowledgments}

The authors thank the Director, CSIR-Indian Institute of Toxicology Research (CSIR-IITR), Lucknow for his support in the present study. The support from University Grants Commission (New Delhi) for providing the research fellowships to Lalit P. Chandravanshi is thankfully acknowledged.

\section{References}

1. Hughes MF, Beck BD, Chen Y, Lewis AS, Thomas DJ (2011) Arsenic exposure and toxicology: a historical perspective. Toxicol Sci 123: 305-332.

2. Wlodarczyk BJ, Palacios AM, Chapa CJ, Zhu H, George TM, et al. (2011) Genetic basis of susceptibility to teratogen induced birth defects. Am J Med Genet C Semin Med Genet 157C: 215-226.

3. Abhyankar LN, Jones MR, Guallar E, Navas-Acien A (2012) Arsenic exposure and hypertension: a systematic review. Environ Heal Perspect 120: 494-500.

4. Berry MD (2007) The potential of trace amines and their receptors for treating neurological and psychiatric diseases. Rev Recent Clin Trials 2: 3-19.

5. Hsu LI, Chen GS, Lee CH, Yang TY, Chen YH, et al. (2013) Use of arsenic-induced palmoplantar hyperkeratosis and skin cancers to predict risk of subsequent internal malignancy. Am J Epidemiol 177: 202-212.

6. Murgo AJ (2001) Clinical trials of arsenic trioxide in hematologic and solid tumors: overview of the National Cancer Institute Cooperative Research and Development Studies. Oncologist 6: 22-28.

7. Núñez $O$, Fernández-Navarro P, Martín-Méndez I, Bel-Lan A, Locutura JF, et al (2016) Arsenic and chromium topsoil levels and cancer mortality in Spain. Environ Sci Pollut Res Int 23: 17664-17675.

8. Tyler CR, Allan AM (2014) The Effects of Arsenic Exposure on Neurological and Cognitive Dysfunction in Human and Rodent Studies: A Review. Curr Environ Health Rep 1: 132-147.

9. Vahidnia A, van der Straaten RJ, Romijn F, Van Pelt J, van der Voet GB, et al. (2007) Arsenic metabolites affect expression of the neurofilament and tau genes: an in vitro study into the mechanism of arsenic neurotoxicity. Toxicol In Vitro 21 1104-1112.

10. Barton AL, McLean B (2013) An unusual case of peripheral neuropathy possibly due to arsenic toxicity secondary to excessive intake of dietary supplements. Ann Clin Biochem 50: 496-500.

11. Concha G, Vogler G, Lezcano D, Nermell B, Vahter M (1998) Exposure to inorganic arsenic metabolites during early human development. Toxicol Sci 44: 185-190.

12. Davis MA, Mackenzie TA, Cottingham KL, Gilbert-Diamond D, Punshon T, et al (2012) Rice consumption and urinary arsenic concentrations in U.S. children. Environ. Health Perspect 120: 1418-1424. 
Citation: Chandravanshi LP, Patel DK (2017) Subchronic Early Life Arsenic Exposure at Low Doses Impaired the Biogenic Amine Neurotransmitter and Nitric Oxide Levels in Different Brain Regions of Rats. J Environ Anal Toxicol 7: 477. doi: 10.4172/2161-0525.1000477

13. Rahman A, Vahter M, Smith AH, Nermell B, Yunus M, et al. (2009) Arsenic exposure during pregnancy and size at birth: a prospective cohort study in Bangladesh. Am J Epidemiol 177: 202-212.

14. Saha KK, Engström A, Hamadani JD, Tofail F, Rasmussen KM, et al. (2012) Pre- and postnatal arsenic exposure and body size to 2 years of age: a cohort study in rural Bangladesh. Environ Health Perspect 120: 1208-1214.

15. von Ehrenstein OS, Poddar S, Yuan Y, Mazumder DG, Eskenazi B, et al. (2007) Children's intellectual function in relation to arsenic exposure. Epidemiology 18: 44-51.

16. Hamadani JD, Tofail F, Nermell B, Gardner R, Shiraji S, et al. (2011) Critical windows of exposure for arsenic-associated impairment of cognitive function in preschool girls and boys: a population based cohort study. Int J Epidemiol 40: $1593-1604$

17. Rosado JL, Ronquillo D, Kordas K, Rojas O, Alatorre J, et al. (2007) Arsenic exposure and cognitive performance in mexican schoolchildren. Environ Health Perspect 115: 1371-1375.

18. Roy A, Kordas K, Lopez P, Rosado JL, Cebrian ME, et al. (2011) Association between arsenic exposure and behavior among 636 first-graders from Torreon, Mexico. Environ Res 111: 670-676.

19. Tsuji JS, Garry MR, Perez V, Chang ET (2015) Low-level arsenic exposure and developmental neurotoxicity in children: A systematic review and risk assessment. Toxicology 337: 91-107.

20. Wasserman GA, Liu X, Parvez F, Factor-Litvak P, Kline J, Siddique AB, et al. (2016) Child Intelligence and Reductions in Water Arsenic and Manganese: A Two-Year Follow-up Study in Bangladesh. Environ Health Perspect 124: 11141120.

21. Myers SL, Lobdell DT, Liu Z, Xia Y, Ren H, et al. (2010) Maternal drinking water arsenic exposure and perinatal outcomes in inner Mongolia, China. J Epidemiol Community Health 64: 325-329.

22. Quansah R, Armah FA, Essumang DK, Luginaah I, Clarke E, et al. (2015) Association of arsenic with adverse pregnancy outcomes/infant mortality: a systematic review and meta-analysis. Environ Health Perspect 123: 412-421.

23. Wo J, Chen G, Liao Y, Song X, Pei L, et al. (2011) Arsenic levels in the soil and risk of birth defects: A population-based case-control study using GIS technology. J Environ. Health 74: 20-25.

24. Chandravanshi LP, Yadav RS, Shukla RK, Singh A, Sultana S, et al. (2014) Reversibility of changes in brain cholinergic receptors and acetylcholinesterase activity in rats following early life arsenic exposure. Int J Dev Neurosci 34: 60-75.

25. Chandravanshi LP, Shukla RK, Sultana S, Pant AB, Khanna VK (2014) Early life arsenic exposure and brain dopaminergic alterations in rats. Int $\mathrm{J}$ Dev Neurosci 38: 91-104.

26. Lu TH, Tseng TJ, Su CC, Tang FC, Yen CC, et al. (2014) Arsenic induces reactive oxygen species-caused neuronal cell apoptosis through JNK/ERK mediated mitochondria-dependent and GRP 78/CHOP-regulated pathways. Toxicol Lett 224: 130-140

27. Kim EK, Choi EJ (2010) Pathological roles of MAPK signaling pathways in human diseases. Biochim Biophys Acta 1802: 396-405.

28. Tamagno E, Parola M, Guglielmotto M, Santoro G, Bardini P, et al. (2003) Multiple signaling events in amyloid betainduced, oxidative stress-dependent neuronal apoptosis. Free Radic Biol Med 35: 45-58.

29. Bardullas U, Limón-Pacheco JH, Giordano M, Carrizales L, Mendoza-Trejo MS, et al. (2009) Chronic low-level arsenic exposure causesgender-specific alterations in locomotor activity, dopaminergic systems, andthioredoxin expression in mice. Toxicol Appl Pharmacol 239: 169-177

30. Delgado JM, Dufour L, Grimaldo JI, Carrizales L, Rodriguez VM, et al. (2000) Effects of arsenite on central monoamines and plasmatic levels of adrenocorticotropic hormone (ACTH) in mice. Toxicol Lett 117: 61-67.

31. Meneses A, Liy-Salmeron G (2012) Serotonin and emotion, learning and memory. Rev Neurosci 23: 543-553.

32. Liu X, Piao F, Li Y (2013) Protective effect of taurine on the decreased biogenic amine neurotransmitter levels in the brain of mice exposed to arsenic. Adv Exp Med Biol 776: 277-287.

33. Tripathi N, Kannan GM, Pant BP, Jaiswal DK, Malhotra PR, et al. (1997) Arsenic-induced changes in certain neurotransmitter levels and their recoveries following chelation in rat whole brain. Toxicol Lett 92: 201-208.
34. Zhang J, Liu X, Zhao L, Hu S, Li S, et al. (2013) Subchronic exposure to arsenic disturbed the biogenic amine neurotransmitter level and the mRNA expression of synthetase in mice brains. Neuroscience 241: 52-58.

35. Rios R, Zarazúa S, Santoyo ME, Sepúlveda-Saavedra J, Romero-Díaz V, et al (2009) Decreased nitric oxide markers and morphological changes in the brain of arsenic-exposed rats. Toxicology 261: 68-75.

36. Rodríguez VM, Limón-Pacheco JH, Carrizales L, Mendoza-Trejo MS, Giordano $M(2010)$ Chronic exposure to low levels of inorganic arsenic causes alterations in locomotor activity and in the expression of dopaminergic and antioxidant systems in the albino rat. Neurotoico Teratol 32: 640-647.

37. Xi S, Guo L, Qi R, Sun W, Jin Y, et al. (2010) Prenatal and early life arsenic exposure induced oxidative damage and altered activities and mRNA expressions of neurotransmitter metabolic enzymes in offspring rat brain. $J$ Biochem Mol Toxicol 24: 368-378.

38. Harooni HE, Naghdi N, Sepehri H, Rohani AH (2009) The role of hippocampa nitric oxide (NO) on learning and immediate, short- and long-term memory retrieval in inhibitory avoidance task in male adult rats. Behav. Brain Res 201: 166-172.

39. Paul V, Ekambaram $P$ (2011) Involvement of nitric oxide in learning \& memory processes. Indian J Med Res 133: 471-478.

40. Akar FY, Ulak G, Tanyeri P, Erden F, Utkan T, et al. (2007) 7-Nitroindazole a neuronal nitric oxide synthase inhibitor, impairs passive-avoidance and elevated plus-maze memory performance in rats. Pharmacol. Biochem Behav 87: 434-443.

41. Vahter M (2009) Effects of arsenic on maternal and fetal health. Annu Rev Nutr 29: 381-399.

42. Pi J, Horiguchi S, Sun Y, Nikaido M, Shimojo N, et al. (2003) A potential mechanism for the impairment of nitric oxide formation caused by prolonged oral exposure to arsenate in rabbits. Free Radic Biol Med 35: 102-113.

43. Zarazúa S, Pérez-Severiano F, Delgado JM, Martínez LM, Ortiz-Pérez D, et al. (2006) Decreased nitric oxide production in the rat brain after chronic exposure arsenic exposure. Neurochem Res 31: 1069-1077.

44. Glowinski J, Iversen LL (1966) Regional studies of catecholamines in the rat brain. I. The disposition of $[3 \mathrm{H}]$ norepinephrine, $[3 \mathrm{H}]$ dopamine and $[3 \mathrm{H}]$ dopa in various regions of the brain. J Neurochem 13: 655- 659.

45. Kim C, Speisky MB, Kharouba SN (1987) Rapid and sensitive method for measuring norepinephrine, dopamine, 5-hydroxytryptamine and their major metabolites in rat brain by high-performance liquid chromatography. Differential effect of probenecid, haloperidol and yohimbine on the concentrations of biogenic amines and metabolites in various regions of rat brain. $\mathrm{J}$ Chromatogr 386: 25-35.

46. Misko TP, Schilling RJ, Salvemini D, Moore WM, Currie MG (1993) A fluorometric assay for the measurement of nitrite in biological samples. Anal Biochem 214: 11-16.

47. Lowry OH, Rosebrough NJ, Farr AL, Randall RJ (1951) Protein measurement with the folin phenol reagent. J Biol Chem 193: 265-275.

48. D'Ardenne K, Eshel N, Luka J, Lenartowicz A, Nystrom LE, Cohen JD (2012) Role of prefrontal cortex and the midbrain dopamine system in working memory updating. Proc Natl Acad Sci U S A 109: 19900-19909.

49. Tully K, Bolshakov VY (2010) Emotional enhancement of memory: how norepinephrine enables synaptic plasticity. Mol Brain 3: 15.

50. Gorenkova NA, Nazarenko IV, Volkov AV, Avruschenko MS, Lapa GB, et al. (2005) Neuropsychological disorders indicative of postresuscitation encephalopaty in rats. Span J Psychol 8: 246-255.

51. Herlenius E, Lagercrantz H (2004) Development of neurotransmitter systems during critical periods. Exp Neurol 1: S8-21.

52. Daré E, Fetissov S, Hökfelt T, Hall H, Ögren SO, et al. (2003) Effects of prenatal exposure to methyl mercury on dopamine mediated locomotor activity and dopamine D2 receptor binding. Naunyn-Schmiedebergs Arch. Pharmacol 36 500-508.

53. Gaspar P, Cases O, Maroteaux L (2003) The developmental role of serotonin: news from mouse molecular genetics. Nat Rev Neurosci 4: 1002-1012.

54. Thomas SA, Palmiter RD (1997) Impaired maternal behavior in mice lacking norepinephrine and epinephrine. Cell 91: 583-592. 
Citation: Chandravanshi LP, Patel DK (2017) Subchronic Early Life Arsenic Exposure at Low Doses Impaired the Biogenic Amine Neurotransmitter and Nitric Oxide Levels in Different Brain Regions of Rats. J Environ Anal Toxicol 7: 477. doi: 10.4172/2161-0525.1000477

55. Rodríguez VM, Carrizales L, Mendoza MS, Fajardo OR, Giordano M (2002) Effects of sodium arsenite exposure on development and behavior in the rat. Neurotoxicol Teratol 24: 743-750.

56. Staller JA, Faraone SV (2007) Targeting the dopamine system in the treatment of attention-deficit/hyperactivity disorder. Exp Rev Neurother 7: 351-362.

57. Kannan GM, Tripathi N, Dube SN, Gupta M, Flora S, et al. (2001) Toxic effects of arsenic (III) on some hematopoietic and central nervous system variables in rats and guinea pigs. J Toxicol Clin Toxicol 39: 675-682

58. Tunbridge EM, Harrison PJ, Weinberger DR (2006) Catechol-omethyltransferase, cognition, and psychosis: Val158Met and beyond. Biol Psychiatry 60: 141-151.

59. Rodríguez VM, Dufour L, Carrizales L, Díaz-Barriga F, Jiménez-Capdeville ME (1998) Effects of oral exposure to mining waste on in vivo dopamine release from rat striatum. Environ Health Perspect 106: 487-491.

60. Tadanobu I, Zhang YF, Shigeo M, Hiroko S, Hiromichi N, et al. (1990) The effect of arsenic trioxide on brain monoamine metabolism and locomotor activity of mice. Toxicol Lett 54: 345-353.

61. Syed F, Chandravanshi LP, Khanna VK, Soni I (2016) Beta-cyfluthrin induced neurobehavioral impairments in adult rats. Chem Biol Interact 5: 19-28.

62. Martinez EJ, Kolb BL, Bell A, Savage DD, Allan AM (2008) Moderate perinatal arsenic exposure alters neuroendocrine markers associated with depression and increases depressive-like behaviors in adult mouse offspring. Neurotoxicology 29: 647-655

63. Huo T, Chang B, Zhang Y, Chen Z, Li W, et al. (2012) Alteration of amino acid neurotransmitters in brain tissues of immature rats treated with realgar. J Pharm Biomed Anal 57: 120-124.
64. Chakraborti D, Rahman MM, Ahamed S, Dutta RN, Pati S, et al. (2016) Arsenic groundwater contamination and its health effects in Patna district (capital of Bihar) in the middle Ganga plain, India. Chemosphere 152: 520-529.

65. Rahman MK, Choudhary MI, Arif M, Morshed MM (2014) Dopamine-ßHydroxylase Activity and Levels of Its Cofactors and Other Biochemical Parameters in the Serum of Arsenicosis Patients of Bangladesh. Int J Biomed Sci 10: 52-60.

66. Guix FX, Uribesalgo I, Coma M, Munoz FJ (2005) The physiology and pathophysiology of nitric oxide in the brain. Prog. Neurobiol 76: 126-152.

67. McCann SM (1997) The nitric oxide hypothesis of brain aging. Exp Gerontol 32: $431-440$.

68. Rivier C (2001) Role of gaseous neurotransmitters in the hypothalamicpituitary-adrenal axis. Ann N Y Acad Sci 933: 254-264.

69. Esplugues JV (2002) NO as a signaling molecule in the nervous system. Br J Pharmacol 135: 1079-1095.

70. Bredt DS, Glatt CE, Hwang PM, Fotuhi M, Dawson TM, et al. (1991) Nitric oxide synthase protein and $\mathrm{mRNA}$ are discretely localized in neuronal populations of the mammalian CNS together with NADPH diaphorase. Neuron 7: 615-624.

71. Dawson TM, Snyder SH (1994) Gases as biological messengers: nitric oxide and carbon monoxide in the brain. J Neurosci 14: 5147-5159.

72. Rodrigo J, Springall DR, Uttenthal O, Bentura ML, Abadia-Molina F, et al (1994) Localization of nitric oxide synthase in the adult rat brain. Philos Trans $R$ Soc Lond B Biol Sci 345: 175-221.

73. Mejia JJ, Diaz-Barriga F, Calderon J, Rios C, Jiménez-Capdeville ME (1997) Effects of lead - arsenic combined exposure on central monoaminergic systems. Neurotoxicol Teratol 19: 489-497. 